\title{
Obesity: Effects on Cardiovascular Disease and its Diagnosis
}

\author{
Boban Mathew, MD, MRCP, DM, Lisa Francis, MD, MRCP, Attila Kayalar, MD, and
} Jesse Cone, $M D$

The higher prevalence of cardiovascular disease in obese individuals is indirectly mediated, to a large extent, by the increased frequency of various well known risk factors like hypertension, diabetes, and dyslipidemia, either individually or as part of the metabolic syndrome. However, there are several ways in which obesity directly affects the cardiovascular system; these will be discussed in detail. We also focus on various challenges posed by obesity in the performance and interpretation of cardiac investigations and how they can be addressed. (J Am Board Fam Med 2008;21:562-8.)

The incidence of obesity started growing to epidemic proportions in the 1980s. Currently more than $30 \%$ of the US population is obese (body mass index $[\mathrm{BMI}] \geq 30)$ and nearly two thirds are overweight (BMI between 25 and 29.9). These figures are expected to rise further if the current trend continues $^{1-3}$ (see Table $1^{4}$ ). There are 2 distinct genetic mechanisms involved in obesity. One is caused by the infrequent presence of certain genes, which produce rare syndromes associated with significant obesity. However, obesity is much more commonly mediated by the presence of other "susceptibility" genes. More than 41 such genetic sites have been identified and in their presence obesity will develop only if there is a favorable environment. ${ }^{5,6}$ These genes control different processes, such as regulation of fat distribution, metabolic rate, response to exercise and diet, control of feeding, and food preferences, etc. But the striking rise in the incidence of obesity, which has happened in the last few decades, is not because of changes in the genetic background of the human race, since these changes take thousands of years to evolve.

This article was externally peer reviewed.

Submitted 29 April 2008; revised 7 August 2008; accepted 12 August 2008.

From the Department of Cardiology (BM, AK, JC) and the Department of Internal Medicine (LF), State University of New York Upstate Medical University, Syracuse.

Funding: none.

Conflict of interest: none declared.

Corresponding author: Boban Mathew, MD, MRCP, DM, Department of Cardiology, SUNY Upstate Medical University, 750 East Adam Street, Syracuse, NY 13210 (E-mail: bmathew6@yahoo.com).
This "epidemic" is mainly caused by rapid lifestyle changes involving eating habits and exercise. .,7 $^{5,}$

Obesity increases adverse cardiac events in many ways. These may be indirectly mediated through risk factors associated with metabolic syndrome like dyslipidemia, hypertension, and glucose intolerance, or effects from sleep disorders associated with obesity. ${ }^{8,9}$ Metabolic syndrome is associated with central or abdominal obesity, with the distribution of fat predominantly in the abdominal viscera rather than the extremities. Waist circumference or waist-hip ratio are useful ways of assessing this type of fat distribution and increased values confer additional cardiovascular risk. In abdominal obesity, there is an increase in the level of various inflammatory markers as well as the occurrence of a prothrombotic state. ${ }^{10,11}$ Many adipokines and other chemical mediators like tumor necrosis factor-alpha, interleukin-6, plasminogen activator inhibitor-1, resistin, lipoprotein lipase, acylation stimulating protein, cholesteryl ester transport protein, retinal binding protein, estrogens, leptin, angiotensinogen, and insulin-like growth factor-1 are present in increased concentrations in obese patients. These have various adverse effects on the cardiovascular system by creating a pro-inflammatory and prothrombotic state as well as causing endothelial damage and vascular hypertrophy. ${ }^{12,13}$ There is also a higher incidence of sleep apnea/ hypoventilation syndromes in obesity, which can affect the heart in different ways.

There are, however, also many direct effects of obesity on the heart and the cardiovascular system, 
Table 1. Increasing Percentage of Overweight and Obese Patients in Different Periods According to the National Health and Nutrition Examination Survey Data

\begin{tabular}{lccc}
\hline & $\begin{array}{c}1976-1980 \\
(\mathrm{n}=11,207)\end{array}$ & $\begin{array}{c}1988-1994 \\
(\mathrm{n}=11,468)\end{array}$ & $\begin{array}{c}1999-2002 \\
(\mathrm{n}=7,494)\end{array}$ \\
\hline Overweight $(\mathrm{BMI} \geq 25)$ & 47 & 56 & 65 \\
Obese $(\mathrm{BMI} \geq 30)$ & 15 & 23 & 31 \\
\hline
\end{tabular}

which are not mediated through components of the metabolic syndrome or through the associated effects of sleep disorders. These will be the main focus of this article. Obesity also poses considerable challenges to making a precise cardiovascular diagnosis because of limitations in physical examination as well as with various investigations like electrocardiograms (EKGs), imaging studies, and cardiac catheterization. We will discuss these limitations and make recommendations as to how these may be addressed.

\section{Pathophysiology of the Circulatory System in Obese Patients}

The adipose tissue has a resting blood flow of 2 to $3 \mathrm{~mL} / 100 \mathrm{~g} / \mathrm{min}$, but can increase up to 10 -fold; this occurs usually after food intake. ${ }^{14}$ However, with increasing obesity the perfusion per unit mass decreases. It falls from $2.36 \mathrm{~mL} / \mathrm{min}$ to $1.53 \mathrm{~mL} /$ min when the percentage of fat increases from $20 \%$ to $36 \%$ of the body weight, and so the increase in cardiac output is not directly proportional to the total fat. ${ }^{15}$ The increased cardiac output in obese patients is to meet the metabolic demand of the adipose tissue and is achieved mainly through an increase in stroke volume. The left ventricular chamber dilates to accommodate the increased venous return and, in turn, develops an eccentric type of hypertrophy to keep the wall stress normal. ${ }^{16}$ The left atrium also enlarges in obese individuals and is initially caused by the increased blood volume and venous return. Later, other factors like left ventricular hypertrophy and diastolic dysfunction may also be responsible for increased left atrial size. ${ }^{17}$ However, in the Strong Heart Study cohort, ${ }^{18}$ it was observed that increases in stroke volume, cardiac output, and left ventricular mass were more closely related to the associated increase in lean body mass than to the amount of fat in obese patients. Left ventricular filling pressure increases with exercise, often to more than $20 \mathrm{~mm} \mathrm{Hg}$, even if it is normal at rest. The left ventricle undergoes hypertrophy of the eccentric type but, less commonly, can be concentric. Initially there is left ventricular diastolic dysfunction with hyperkinetic systole but with longer duration of obesity diastolic dysfunction progressively worsens and gradually systolic dysfunction also sets in. ${ }^{19}$

Cardiomyopathy of obese individuals (adipositas cordis) is caused by a direct effect of obesity on the heart. Initially, the increase in the fat content of the heart is because of a metaplastic phenomenon and is not an infiltrative process. Various tissues of heart, like the sinus node, atrioventricular node, right bundle branch, and the myocardium near the atrioventricular ring, are replaced by fat cells. These can occasionally cause conduction defects like sinoatrial block, bundle branch block, and, rarely, atrioventricular block. ${ }^{20}$ Subsequently, irregular bands of adipose tissue may separate and cause pressure-induced atrophy of the myocardial cells. These adipose cells may also secrete locally active molecules like adipokines, which indirectly cause injurious effects on the adjacent myocardial cells. Accumulation of triglycerides in nonfat cells like myocytes can also directly cause cell dysfunction because of lipotoxicity. ${ }^{21}$

\section{Congestive Heart Failure}

Several factors primarily caused by obesity, like increased blood volume, elevated cardiac output, left ventricular hypertrophy, and left ventricular diastolic dysfunction, in addition to adipositas cordis, play a role in causing heart failure. ${ }^{22}$ This is in addition to indirect effects mediated through other frequently coexisting conditions like diabetes, hypertension, and coronary artery disease.

Clinical assessment for heart failure is often difficult in obese patients for several reasons. Dyspnea during exertion and leg edema can occur even without congestive heart failure. They can have orthopnea caused by the protuberant abdominal contents pressing on the diaphragm when they are recumbent. Physical examination is complicated because 
neck veins are difficult to see, heart and breath sounds are distant, and the liver, even if enlarged because of right heart failure, is difficult to feel.

In the Framingham heart study, after 14 years of follow-up for 5881 patients (mean age, 55 years; $54 \%$ women) heart failure developed in 496. After adjustment for established risk factors there was a calculated increase in the risk of developing heart failure by $5 \%$ in men and $7 \%$ in women for each increment of 1 above 30 on the BMI. The hazard ratio was 2.12 in women (95\% CI, 1.51-2.97) and 1.9 in men (95\% CI, 1.3-.79) who were obese. ${ }^{23}$

Ejection fraction of $<40 \%$ was seen in $42 \%$ of obese compared with $54 \%$ of normal-weight patients with heart failure. Thus, there are more patients with diastolic heart failure among the obese. Approximately $11 \%$ of heart failure in men and $14 \%$ in women in the community are because of obesity alone. ${ }^{23}$

\section{Arrhythmias}

There is an increase in the incidence of sudden cardiac death and arrhythmias in obesity. ${ }^{24}$ Fatal arrhythmias may be the most frequent cause of death among obese patients. According to the Framingham data, sudden cardiac death was 40 times higher in obese men and women. ${ }^{24}$ In another study of severely obese individuals, this was 6-fold and 12 -fold higher in those aged 25 to 34 years and 35 to 44 years, respectively. ${ }^{25}$ In the NHANES III study, $30 \%$ of obese patients with glucose intolerance had a prolonged corrected QT (QTc) interval. Schouten et $\mathrm{al}^{26}$ found that $8 \%$ of obese individuals had a QTc interval of more than 0.44 seconds and, in $2 \%$, it was more than 0.46 seconds. A QTc interval of more than 0.42 seconds was associated with increased mortality in "healthy" obese patients followed for 15 years. QT dispersion, which measures the difference in duration between the maximum and the minimum QT interval in different leads in the EKG is a good noninvasive measurement for quantifying the degree of myocardial repolarization inhomogeneity, which was also increased in the obese. Both QTc interval and QT dispersion are mediated by changes in sympatheticvagal balance. Catecholamine levels are increased in the obese. ${ }^{27}$ In addition, increased free fatty acid levels in the obese may also affect repolarization. In patients with myocardial infarction, there is a relation between ventricular arrhythmias and long- chain saturated fatty acid level. Various changes occur in the autonomic system with weight gain. A $10 \%$ increase in body weight causes a decrease in parasympathetic tone and increase in heart rate. On the other hand, heart rate decreases with weight reduction. There is a significant improvement in heart rate variability with $10 \%$ weight loss. Both increased resting heart rate and decreased heart rate variability are predictors of mortality, independent of the ejection fraction. ${ }^{28}$

In a study of obese patients without clinical heart disease, the prevalence of late potentials (high-frequency, low-amplitude signals at the terminal part of the QRS complex demonstrated using high-resolution signal averaged recording) are seen to be increased proportionately with BMI. The presence of late potentials has been documented to be associated with increased risk of ventricular arrhythmias in several cardiac conditions and is present in less than $3 \%$ of normal controls. In those with a BMI score between 31 to 40,41 to 50 , and $>50$, the incidence of late potentials were $35 \%, 86 \%$ and $100 \%$, respectively. This increased frequency may be related to fat and mononuclear infiltration, fibrosis, focal myocardial disarray, or myocyte hypertrophy. $^{29}$

\section{Coronary Artery Disease}

Obesity is an independent predictor of coronary artery disease, as observed in the Framingham heart study, ${ }^{30}$ Manitoba study, ${ }^{31}$ and Harvard public health nurses study. ${ }^{32}$ In the Framingham cohort, patients aged 28 to 62 years were followed for a mean of 26 years. Among men younger than 50 years, the heaviest group experienced twice the risk of coronary disease compared with the leanest group. The risk was increased 2.4-fold among obese women of similar age, and this was after adjusting for the influence of other major cardiovascular risk factors. ${ }^{30}$ Autopsy among 15 to 34 year olds who died from accidental causes revealed plaques and ulceration in the coronary arteries and abdominal aorta, the extent of which correlated with the amount of abdominal fat and BMI (PDAY study). ${ }^{33}$ Obesity accelerates atherosclerosis decades before clinical manifestations appear and this remained significant even after adjustment of other risk factors like high cholesterol, hypertension, smoking, and increased HbA1c. ${ }^{30}$ The density of macrophages per $\mathrm{mm}^{2}$ of plaques also correlated with visceral obesity. ${ }^{33}$ 
After coronary artery bypass surgery also there are more adverse outcomes in obese patients. ${ }^{34}$ They have increased incidence of postoperative thromboembolism, infections of the sternum, and saphenous vein harvest sites. There is also a higher incidence of atrial arrhythmias. ${ }^{34}$ However mortality or postoperative cerebrovascular events were not significantly higher. Even pulmonary complications were comparable, except in the severely obese (BMI >35) and when complicated by diabetes, renal dysfunction or age $>60 .{ }^{35}$

\section{Hypertension}

Among men, the prevalence of hypertension is $15 \%$ in those with $\mathrm{BMI}<25$ and $42 \%$ if $\mathrm{BMI}$ is $>30$; in women, these are $15 \%$ and $38 \%$, respectively. ${ }^{36}$ Blood pressure is the product of cardiac output and systemic vascular resistance, and cardiac output is increased in obese patients because of increased blood flow to the adipose tissue. ${ }^{15} \mathrm{We}$ should expect the systemic vascular resistance to be low in obese individuals because of the increased cross-sectional area of the vascular bed. However, it is often inappropriately normal or even high, and this increases the likelihood of hypertension. Various factors like low-grade inflammation mediated through adipokines, hyperinsulinemia, and insulin resistance, over-activity of the sympathetic nervous system and a disordered sleep pattern increase the systemic vascular resistance in obese patients. ${ }^{37}$ With increasing severity of obesity, hypertension becomes more prevalent. It may initially be diurnal, especially if there is coexisting sleep apnea. ${ }^{37}$

On the right side also there is an increase in the filling pressures, systolic pressure, and pulmonary vascular resistance. Increased pulmonary vascular resistance may be because of a combination of intrinsic pulmonary disease, sleep apnea/hypoventilation, recurrent pulmonary thromboembolism, or left ventricular dysfunction, all of which are more common in obese individuals. Pulmonary artery pressure is elevated in more than $50 \%$ of obese patients but usually only to a mild degree. ${ }^{19}$ Fifteen percent to $20 \%$ of patients with obstructive sleep apnea have pulmonary hypertension. This is often mild and ranges from 30 to $35 \mathrm{~mm} \mathrm{Hg}$ and is rare in the absence of daytime hypoxia. EKG signs of right ventricular overload are very late manifestations. Nocturnal dysrhythmias, right and left heart failure, myocardial infarction, stroke, and mortality are more common in those with obstructive sleep apnea. $^{38}$

\section{Stroke}

Increased BMI and waist-hip ratio are independent risk factors for stroke, even after adjusting for hypertension, hypercholesterolemia, and diabetes. In the prospective Physician's Health study cohort of 21,414 men, those patients with BMI between 25 and $30(8,105 \mathrm{men})$ and $>30(1,184 \mathrm{men})$ had a multiple adjusted relative risk of total stroke of 1.32 (95\% CI, 1.14-1.54) and 1.91 (95\% CI, 1.45-2.52), respectively, compared with men with $\mathrm{BMI}<25$. In these groups the relative risk of ischemic stroke was 1.35 (95\% CI, 1.15-1.59) and 1.87 (95\% CI, 1.38 2.54) and hemorrhagic stroke was 1.25 (95\% CI, $0.84-1.88$ ) and 1.92 (95\% CI, 0.94-3.93), respectively. ${ }^{39}$ With each 1-unit increase in BMI score, the multiple adjusted rate of ischemic stroke increased by $4 \%$ and $6 \%$ for hemorrhagic stroke. The underlying mechanisms by which increased BMI score affects stroke risk, independent of established risk factors such as hypertension and diabetes, is not fully understood. This could be mediated by the prothrombotic (higher levels of plasminogen activator inhibitor-1 antigen and activity, fibrinogen, von Willebrand factor, and factor VII) and proinflammatory state (increased levels of C-reactive protein and lymphokines) in obesity. ${ }^{39,40}$

\section{Echocardiography}

Large accumulation of subepicardial fat can mimic pericardial effusion (pseudopericardial effusion). Lipomatous hypertrophy caused by fat deposition in the interatrial septum can cause it to be up to more than $20 \mathrm{~mm}$ thick and can even suggest a tumor. ${ }^{41}$ Left ventricular diastolic dysfunction is very common. When compared with normal people, subclinical changes in the structure and function of the left ventricle, such as differences in the regional or global strain, were identified in asymptomatic obese patients many years before they developed signs and symptoms of heart failure. ${ }^{42}$ Poor images are commonly a problem in obese individuals and techniques like tissue Doppler and pulmonary venous Doppler may be useful. ${ }^{43}$

\section{Electrocardiogram}

Interplay between several factors, such as horizontal displacement of the heart by the elevated dia- 
phragm, cardiac hypertrophy, increase in the distance between the heart and the electrodes, and coexisting sleep apnea/obesity/hypoventilation syndrome, tend to modify the EKG in obese patients. The EKG may show low voltage, leftward axis, flat inferolateral $T$ waves, left atrial enlargement, increased false positive criteria for inferior wall myocardial infarction, and less prevalence of left ventricular hypertrophy than that based on echo criteria (only around two thirds). ${ }^{44}$ The left ventricular forces are more posteriorly and laterally oriented with deep $\mathrm{S}$ waves in $\mathrm{V} 3$ and tall $\mathrm{R}$ waves in aVL. The sum of $R$ wave in aVL and $S$ wave in $\mathrm{V} 3$, if more than $35 \mathrm{~mm}$ in men and $25 \mathrm{~mm}$ in women, has a sensitivity of $49 \%$ and a specificity 93\% when compared with echo in diagnosing left ventricular hypertrophy and is more helpful than many of the more commonly used voltage criteria. ${ }^{20}$ With weight loss, the QRS amplitude may increase, decrease, or have no change. ${ }^{45}$

\section{Stress Tests and Cardiac Catheterization}

The diagnosis of coronary artery disease also poses many challenges in the obese. Stress EKG is difficult because of resting EKG abnormalities caused by obesity and difficulty in performing adequate exercise. Nuclear imaging is plagued by attenuation artifacts and higher incidence of false positives. Cardiac catheterization and nuclear imaging is often not possible because of weight limitations of the table; transesophageal dobutamine stress echo may be a good safe alternative even though it is not widely used. For cardiac catheterization, radial approach is preferable. With femoral access, the increased volume of adipose tissue to be passed through by the needle to enter the femoral artery causes difficulty in hemostasis even though various closure devices currently available makes this less challenging than in the past. Duke university catheterization lab data from1986 to 1997 in 9405 patients show that obesity increased from $20 \%$ to $33 \%$ during this period. ${ }^{46}$ Even though obese patients were younger and had a higher percentage of single vessel disease, they had more comorbidity, which resulted in increased clinical events in the 30 days after the test. Inpatient medical cost was also increased. ${ }^{46}$

\section{Conclusions}

Obesity affects the cardiovascular system directly in many ways, in addition to its indirect effects, and it increases morbidity and mortality. Technical difficulties make cardiac investigations difficult to perform and interpret in obese patients. Halting this obesity epidemic is an important hurdle we must overcome in our effort to reduce the burden of cardiovascular diseases in the population.

\section{References}

1. Flegal KM, Carroll MD, Ogden CL, Johnson CL. Prevalence and trends in obesity among US adults, 1999-2000. JAMA 2002;288:1723-7.

2. Kucmarski RJ, Flegal KM, Campbell SM, Johnson CL. Increasing prevalence of overweight among US adults: The National Health and Nutrition Examination Surveys, 1960 to 1991. JAMA 1994;272:20511.

3. Mokdad AH, Serdula MK, Dietz WH, Bowman BA, Marks JS, Koplan JP. The spread of obesity epidemic in the United States, 1991-1998. JAMA 1999;282: 1519-22.

4. Ogden CL, Carroll MD, McDowell MA, Flegal KM. Obesity among adults in the United States-no change since 2003-2004. NCHS data brief no 1 . Hyattsville (MD): National Center for Health Statistics; 2007.

5. Grundy SM, Brewer HB, Cleeman JI, et al. Definition of metabolic syndrome: Report of the National Heart, Lung, and Blood Institute/American Heart Association conference on scientific issues related to definition. Circulation 2004;109:433-8.

6. Snyder EE, Walts B, Perusse L, et al. The human obesity gene map: the 2003 update. Obes Res 2004; 12:369-439.

7. Olshansky SJ, Passaro DJ, Hershow RC, et al. A potential decline in life expectancy in the United States in the 21st century. N Engl J Med 2005;352: $1138-45$.

8. Malik S, Wong ND, Franklin SS, et al. Impact of the metabolic syndrome on mortality from coronary heart disease, cardiovascular disease and all causes in United States adults. Circulation 2004;110:1245-50.

9. Shamsuzzaman AS, Winnicki M, Lanfranchi $P$, et al. Elevated C-reactive protein in patients with obstructive sleep apnea. Circulation 2002;105:2462-4.

10. Kern PA, Saghizadeh M, Ong JM, Bosch RJ, Deem $\mathrm{R}$, Simsolo RB. The expression of tumor necrosis factor in human adipose tissue: regulation by obesity, weight loss and relationship to lipoprotein lipase. J Clin Invest 1995;95:2111-9.

11. Hotamisligil GS, Arner P, Caro JF, Atkinson RL, Spiegelman BM. Increased adipose tissue expression of tumor necrosis factor-alfa in human obesity and insulin resistance. J Clin Invest 1995;95:2409-15.

12. Lundgren CH, Brown SL, Nordt TK, Sobel BE, Fujii S. Elaboration of type-1 plasminogen activator inhibitor from adipocytes. A potential pathogenetic 
link between obesity and cardiovascular disease. Circulation 1996;93:106-10.

13. Steppan CM, Bailey ST, Bhat S, et al. The hormone resistin links obesity to diabetes. Nature 2001;409: 307-12.

14. Larsen OA, Lassen NA, Quaade FN. Blood flow through the human adipose tissue determined with radioactive xenon. Acta Physiol Scand 1966;66:337-45.

15. Summers LK, Samra JS, Humphreys SM, Morris RJ, Frayn KN. Subcutaneous abdominal adipose tissue blood flow: variation within and between subjects and relationship to obesity. Clin Sci (Lond) 1996;91: 679-83.

16. Kaltman AJ, Goldring RM. Role of circulatory congestion in the cardiorespiratory failure of obesity. Am J Med 1976;60:645-53.

17. Ku CS, Lin SL, Wang DJ, Chang SK, Lee WJ. Left ventricular filling in young normotensive obese adults. Am J Cardiol 1994;73:613-5.

18. Collis T, Devereux RB, Roman MJ, et al. Relations of stroke volume and cardiac output to body composition: the strong heart study. Circulation 2001; 103:820-5.

19. De Scheerder I, Cuvelier C, Verhaaren R, De Buyzere M, De Backer G, Clement D. Restrictive cardiomyopathy caused by adipositas cordis. Eur Heart J 1987;8:661-3.

20. Balsaver AM, Morales AR, Whitehouse FW. Fat infiltration of myocardium as a cause of cardiac conduction defect. Am J Cardiol 1967;19:261-5.

21. Zhou YT, Grayburn P, Karim A, et al. Lipotoxic heart disease in obese rats: implications for human obesity. Proc Natl Acad Sci USA 2000;97:1784-9.

22. Poirier P, Giles TD, Bray GA, et al. Obesity and cardiovascular disease: pathophysiology, evaluation and effect of weight loss: an update of the 1997 American Heart Association Scientific Statement on Obesity and Heart Disease from the Obesity Committee of the Council on Nutrition, Physical Activity, and Metabolism. Circulation 2005;113:898-918.

23. Kenchaiah S, Evans JC, Levy D, et al. Obesity and the risk of heart failure. N Engl J Med 2002;347: 305-13.

24. Kannel WB, Plehn JF, Cupples LA. Cardiac failure and sudden cardiac death in the Framingham study. Am Heart J 1988;115:869-75.

25. Drenick EJ, Bale GS, Seltzer F, Johnson DG. Excessive mortality and causes of death in morbidly obese men. JAMA 1980;243:443-5.

26. Schouten EG, Dekker JM, Meppelink P, Kok FJ, Vandenbroucke JP, Pool J. QT interval prolongation predicts cardiovascular mortality in an apparently healthy population. Circulation 1991;84:1516-23.

27. Esposito K, Nicolletti G, Marzano S, et al. Autonomic dysfunction associates with prolongation of QT intervals and blunted night $\mathrm{BP}$ in obese women with visceral obesity. J Endocrinol Invest 2002;25:RC32-5.

28. Sccareccia F, Pannozzo F, Dima F, et al. Heart rate as a predictor of mortality: the MATISS project. Am J Public Health 2001;91:1258-63.

29. Lalani AP, Kanna B, John J, Ferrick KJ, Huber MS, Shapiro LE. Abnormal signal averaged electrocardiogram (SAECG) in obesity. Obes Res 2000;8:20-8.

30. Hubert HB, Feinleib M, McNamara PM, Castelli WP. Obesity as an independent risk factor for cardiovascular disease: a 26-year follow-up of participants in the Framingham Heart Study. Circulation 1983;67:968-77.

31. Rabkin SW, Mathewson FA, Hsu PH. Relation of body weight to development of ischemic heart disease in a cohort of young North American men after a 26-year observation period: the Manitoba study. Am J Cardiol 1977;39:452-8.

32. Manson JE, Colditz GA, Stampfer MJ, et al. A prospective study of obesity and risk of coronary heart disease in women. N Engl J Med 1990;322:882-9.

33. McGill HC, McMahan CA, Malcom GT, Oalmann MC, Strong JP. Relation of glycohemoglobin and adiposity to atherosclerosis in youth. Pathobiological Determinants of Atherosclerosis in Youth (PDAY) Research Group. Arterioscler Thromb Vasc Biol 1995; $15: 431-40$.

34. Marik P, Varon J. The obese patient in the ICU. Chest 1998;113:492-8.

35. Rose DK, Cohen MM, Wigglesworth DF, DeBoer DP. Critical respiratory events in the postanesthesia care unit. Patient, surgical, and anesthetic factors. Anesthesiology 1994;81:410-8.

36. Brown CD, Higgins M, Donato KA, et al. Body mass index and the prevalence of hypertension and dyslipidemia. Obes Res 2000;8:605-19.

37. Johnson AL, Cornoni JC, Cassel JC, Tyroler HA, Heyden S, Hames CG. Influence of race, sex and weight on blood pressure in young adults. Am J Cardiol 1975;35:523-30.

38. Partinen M, Jamieson A, Guilleminault C. Longterm outcome for obstructive sleep apnea syndrome patients. Chest 1998;94:1200-4.

39. Kurth T, Gaziano JM, Berger K, et al. Body mass index and the risk of stroke in men. Arch Intern Med 2002;162:2557-62.

40. Rost NS, Wolf PA, Kase CS, et al. Plasma concentration of C-reactive protein and risk of ischemic stroke and transient ischemic attack: the Framingham study. Stroke 2001;32:2575-9.

41. Alpert MA, Kelly DL. Value and limitations of echocardiography assessment of obese patients. Echocardiography 1986;3:261-72.

42. Wong CY, O'Moore-Sullivan T, Leano R, Byrne N, Beller E, Marwick TH. Alterations of left ventricular myocardial characteristics associated with obesity. Circulation 2004;110:3081-7. 
43. Peterson LR, Waggoner AD, Schechtman KB, et al. Alterations in left ventricular structure and function in young healthy obese women: assessment by echocardiography and tissue Doppler imaging. J Am Coll Cardiol 2004;43:1399-404.

44. Alpert Ma, Terry BE, Cohen MV, Fan TM, Painter JA, Massey CV. The electrocardiogram in morbid obesity. Am J Cardiol 2000;85:908-10.
45. Casale PN, Devereux RB, Kligfield P, et al. Electrocardiographic detection of left ventricular hypertrophy: development and prospective validation of improved criteria. J Am Coll Cardiol 1985;6:572-80.

46. Eisenstein EL, Shaw LK, Nelson CL, Anstrom JK, Hakim Z, Mark DB. Obesity and long-term clinical and economic outcomes in coronary artery disease patients. Obes Res 2002;10:83-91. 